\section{Measurement and Analyses of Growth and Stress Parameters of Viburnum odoratissimum (Ker-gawl) Grown in a Multi-pot Box System}

\author{
Suat Irmak ${ }^{1}$ \\ University of Nebraska-Lincoln, Institute of Agriculture and Natural Resources. \\ Department of Biological Systems Engineering, P.O. Box 830726, Lincoln, \\ NE 68583-0726
}

\begin{abstract}
Dorota Z. Haman
University of Florida, Agricultural and Biological Engineering Department, P.O. Box 110570, Gainesville, FL 32611-0570
\end{abstract}

\begin{abstract}
Ayse Irmak
University of Nebraska-Lincoln, Institute of Agriculture and Natural Resources. Department of Biological Systems Engineering, P.O. Box 830726, Lincoln, NE 68583-0726
\end{abstract}

James W. Jones and Kenneth L. Campbell

University of Florida, Agricultural and Biological Engineering Department, P.O. Box 110570, Gainesville, FL 32611-0570

\section{Thomas L. Crisman \\ University of Florida, Department of Environmental Engineering Sciences, P.O. Box 116350, Gainesville, FL 32611-6350}

Additional index words. irrigation, multi-pot box system, MPBS, crop water stress index, water potential, resistance, ornamentals

\begin{abstract}
Two colors (white and black) of a recently introduced irrigation-plant production system [multi-pot box system (MPBS)] for container-grown nurseries were researched and results were compared with those obtained from the sprinkler-irrigated conventional (control) system (CS). Experiments were carried out in summer and fall of 2001 in Gainesville, Fla. Plant growth [growth index (GI), growth rate (GR), and dry matter] and stress parameters [stomatal resistance $(r)$, crop water stress index (CWSI), plant water potential (PWP), and substrate temperature (ST)] were measured and analyzed for Viburnum odoratissimum (Ker-gawl). In both seasons, plants grown in the white MPBS had significantly higher GI and GR as compared to the plants in the black MPBS and CS. In summer, plants in the white MPBS reached marketable size about 17 days and 86 days earlier than those in the black MPBS and CS, respectively. In fall, they reached marketable size about 25 and 115 days earlier than those plants in the black MPBS and CS, respectively. Plants in the white and black MPBSs showed exponential growth rate in summer with plants in the white MPBS having significantly higher growth rate (greater slope) than the other two treatments. In both seasons, plants in the white MPBS produced the highest amount of dry matter. In general, plants in the white MPBS had lower $r_{s}$ values to vapor transport compared to the other two treatments, and the black MPBS treatment had lower $r_{s}$ values than the CS in both seasons. The CWSI values of the plants in both white and black MPBSs were significantly lower than the CS. In both seasons, $\mathrm{ST}$ in the black MPBS and CS exceeded the critical value of $40^{\circ} \mathrm{C}$ several times. The $\mathrm{ST}$ of $>40^{\circ} \mathrm{C}$ is often reported to significantly reduce the plant growth and cause root death and/or injury for container-grown plants. Overall, the white MPBS provided a better environment for root development and plant growth under these experimental conditions. Results strongly suggest that there is a potential opportunity of using MPBS for irrigation and production of nursery plants. These important findings suggest that, in practice, producing nursery plants in a shorter period of time by using white MPBS will result in significant savings of energy, water, chemicals, and other inputs and thereby reducing the costs and increasing profits.
\end{abstract}

Received for publication 22 Jan. 2003. Accepted for publication 23 Mar. 2004. Florida Agricultural Experiment Station journal series R-08938. The authors wish to acknowledge the excellent technical assistance of Danny Burch in the Agricultural and Biological Engineering Department at the University of Florida. The mention of trade names or commercial products is solely for the information of the reader and does not constitute an endorsement or recommendation for use.

${ }^{1}$ To whom reprint requests should be addressed: e-mail sirmak2@unlnotes.unl.edu.
One of the major challenges confronting nursery growers is to conserve water and minimize or prevent runoff while meeting the water requirements of plants growing in the containers. Currently, most of the nursery growers in Florida and other states use overhead sprinkler irrigation systems for irrigation. However, studies (Karam and Niemiera, 1994; Weatherspoon and Harrell, 1980) suggest that the overhead sprinkler system is a very inefficient method to irrigate container-grown nursery plants due to a significant amount of runoff and evaporation losses during or after irrigation. However, in general, the overhead sprinkler system is one of the most economically feasible methods of irrigating plants in small containers, \#12 L, (Karam and Niemiera, 1994) when material, labor costs, and projected plant market values are considered (Weatherspoon and Harrell, 1980).

Improvement in the efficiency of the irrigation systems used in the container nursery industry and development of new irrigation systems that utilize water resources more efficiently is not only a challenge to Florida's growers but to water management agencies and nursery growers in other states in the U.S. as well. For example; Kabashima (1993) reports that growers throughout California are required to evaluate the potential liability of runoff from their operations because of the California Safe Drinking Water and Toxic Enforcement Act of 1986, The Ground Water Protection Program (California Pesticide Contamination Prevention Act of 1985), and zero tolerance limits set by local agencies and advocated by environmental groups. Similar problems are being studied in other states.

Recently, a new irrigation-plant production system [multi-pot box system (MPBS)] has been introduced (Haman et al., 1998; Irmak et al., 2001; Irmak et al., 2003). A detailed description of the MPBS was reported by Irmak et al. (2001, 2003). The seasonal irrigation water use efficiency (SIWUE), irrigation efficiency (IE), irrigation applications, and runoff from the MPBS system were analyzed and reported by the same researchers. The above-mentioned characteristics of the system were compared to the conventional sprinklerirrigated plant production system (CS) by Irmak et al. (2003) in two seasons (summer and fall) in Gainesville, Fla. In their study, the CS (overhead sprinklers) represented the typical irrigation-plant production system used by the majority of nursery growers. They reported that the IEs of the white and black MPBSs were significantly higher than the IE of the CS in both seasons. By using the MPBS, at least $75 \%$ of water saving was achieved compared to the CS. Since the MPBS was designed to capture rain and excess irrigation water, the irrigation demand of the plants grown in these systems was significantly reduced. In addition, the MPBSs resulted in much less runoff compared to the CS treatment. In the summer, the total runoff from the white and black boxes was only $18 \%$ of the runoff from the CS, and in the fall, on the average the total runoff from the MPBS was only about $10 \%$ of the runoff occurring from the CS, resulting less chemical leaching 
to the ground water. They concluded that the white MPBS presented a potential opportunity for efficient irrigation and significant water savings for container-grown nurseries.

To evaluate the growth and stress parameters of plants grown under different irrigation-plant production systems under different management practices, a variety of indexes and/or indicators, such as growth index (GI), crop water stress index (CWSI), plant water potential (PWP), and substrate temperature (ST) can be used. It is known that water stress can cause significant yield or plant biomass reductions and reduce yield quality. The degree of yield/biomass reduction can be more severe if plants experience water stress at early growth stages. Thus, quantification of the level of stress would help to evaluate and compare different irrigation-plant production systems in terms of which system provides a better environment for plant growth.

Canopy temperature $\left(\mathrm{T}_{\mathrm{c}}\right)$ offers a good indication of plant stress. This approach is based on the assumption that, as water becomes a limiting factor, transpiration rate is reduced causing less evaporative cooling of leaves thereby increasing $T_{c}$ in relation to air temperature $\left(\mathrm{T}_{\mathrm{a}}\right)$. Two approaches (empirical and theoretical) to quantifying the CWSI are available. In the empirical approach, the CWSI is determined from measured canopy temperature (using infrared thermometers or other instruments), air temperature, and other climate variables (Idso et al., 1981). The method based on a theoretical equations (energy balance) was developed by Jackson et al. (1981). In Jackson's method, the difference between canopy and air temperature $\left(T_{c}-T_{a}\right)$ is estimated from energy balance equations and is related to the CWSI. These two CWSI methods yield similar results under complete sun or complete shade (Reginato, 1983). Both CWSI concepts have been used by researchers for many years for quantifying crop water stress and for irrigation scheduling of agronomic crops (Howell et al., 1984; Irmak et al., 2000; Nielsen and Gardner, 1987; Pinter and Reginato, 1982; O'Toole et al., 1984; Reginato, 1983; Reginato and Howe, 1985; Reginato and Garrett, 1987; Wanjura et al., 1990). However, the use of CWSI to quantify the stress of horticultural crops grown under different irrigation-production systems has been limited. This might be due to the complexity of the method and/or the existence of significant numbers of horticultural plant species. In this study, the method outlined by Jackson et al. (1981) was used to quantify the level of crop stress.

\section{Jackson's CWSI method}

The basic energy balance for a crop canopy surface, as derived by Jackson (1982), can be written as

$$
\mathrm{R}_{\mathrm{n}}=\mathrm{G}+\mathrm{H}+\lambda \mathrm{E}
$$

where $R_{n}$ is the net radiation $\left(M J \cdot m^{-2} \cdot d^{-1}\right), G$ is the heat flux below the canopy $\left(\mathrm{MJ} \cdot \mathrm{m}^{-2} \mathrm{~d}^{-1}\right)$, $\mathrm{H}$ is the sensible heat flux from canopy to air $\left(\mathrm{MJ} \cdot \mathrm{m}^{-2} \cdot \mathrm{d}^{-1}\right), \lambda \mathrm{E}$ is the latent heat flux to the air $\left(\mathrm{MJ} \cdot \mathrm{m}^{-2} \cdot \mathrm{d}^{-1}\right)$. In their simplest forms, $\mathrm{H}$ and $\lambda \mathrm{E}$ can be expressed as:

$$
\begin{aligned}
& H=\rho c_{p}\left(T_{a}-T_{a}\right) / r_{a} \\
& \lambda E=\rho c_{p}\left(e_{s}-e_{a}\right) /\left[\gamma\left(r_{a}+r_{s}\right)\right]
\end{aligned}
$$

where, $\rho=$ density of air $\left(\mathrm{kg} \cdot \mathrm{m}^{-3}\right), c_{\mathrm{p}}=$ heat capacity of air $\left(\mathrm{MJ} \cdot \mathrm{kg}^{-1} \cdot{ }^{\circ} \mathrm{C}^{-1}\right), \mathrm{T}_{\mathrm{c}}=$ canopy surface temperature $\left({ }^{\circ} \mathrm{C}\right), \mathrm{T}_{\mathrm{a}}=$ air temperature $\left({ }^{\circ} \mathrm{C}\right), \mathrm{e}_{\mathrm{s}}=$ saturated vapor pressure $(\mathrm{kPa})$ at $\mathrm{T}_{\mathrm{c}}, \mathrm{e}_{\mathrm{a}}=$ vapor pressure of the air $(\mathrm{kPa}), \gamma=$ psychrometric constant $\left(\mathrm{kPa} \cdot{ }^{\circ} \mathrm{C}^{-1}\right), \mathrm{r}_{\mathrm{a}}=$ aerodynamic resistance $\left(\mathrm{s} \cdot \mathrm{m}^{-1}\right), \mathrm{r}_{\mathrm{s}}=$ stomatal resistance to vapor transport $\left(\mathrm{s} \cdot \mathrm{m}^{-1}\right)$. Combining Eqs. 1 to 3, assuming that $\mathrm{G}$ is negligible and defining $\Delta$ as the slope of the saturated vapor pressure versus temperature relation $\left(e_{s}-e_{a}\right) /\left(T_{c}-T_{a}\right)$ in units of $\mathrm{kPa} \cdot{ }^{\circ} \mathrm{C}^{-1}$, the difference between the canopy and the air temperatures can be related to the vapor pressure deficit of the air $\left(e_{s}-e_{a}\right)$, net radiation, and the aerodynamic and stomatal resistance (Jackson et al., 1982) as Eq [4]:

$$
T_{c}-T_{a}=\frac{r_{a} R_{n}}{\rho c_{p}} \cdot \frac{\gamma\left(1+r_{s} / r_{2}\right)}{\Delta+\gamma\left(1+r_{s} / r_{2}\right)}-\frac{e_{s}-e_{a}}{\Delta+\gamma\left(1+r_{s} / r_{2}\right)}
$$

Under constant environmental conditions, the value of $T_{c}-T_{a}$ will vary with the $r_{s}$, and thus $r_{s}$ will determine the upper (UL) and lower (LL) limits of the $T_{c}-T_{a}$. Therefore, the upper limit of $T_{c}-T_{a}$ can be determined from Eq. 4 by allowing the $r_{s}$ to increase without limit, i.e., as $r_{\mathrm{s}} \approx \infty$ :

$$
\left(T_{c}-T_{a}\right)_{U L}=I_{a} R_{n} / \rho c_{p}
$$

The lower limit of the $\mathrm{T}_{c}-\mathrm{T}_{\mathrm{a}}$ can be determined by setting $r_{s}=0$ in Eq. 4 :

$$
\left(\mathrm{T}_{\mathrm{c}}-\mathrm{T}_{\mathrm{a}}\right)_{\mathrm{LI}}=\frac{\mathrm{r}_{\mathrm{a}} \mathrm{R}_{\mathrm{I}}}{\rho c_{\mathrm{P}}} \cdot \frac{\gamma}{\Delta+\gamma}-\frac{e_{\mathrm{s}}-e_{\mathrm{a}}}{\Delta+\gamma}
$$

Then, using the $\mathrm{T}_{\mathrm{c}}-\mathrm{T}_{\mathrm{a}},\left(\mathrm{T}_{\mathrm{c}}-\mathrm{T}_{\mathrm{a}}\right)_{\mathrm{UL}}$, and $\left(\mathrm{T}_{\mathrm{c}}\right.$ $\left.-\mathrm{T}_{\mathrm{a}}\right)_{\mathrm{LL}}$, the CWSI value can be calculated as

$$
\text { CWSI }=\frac{\left(T_{c}-T_{a}\right)-\left(T_{c}-T_{a}\right)_{L I}}{\left(T_{c}-T_{a}\right)_{I I}-\left(T_{c}-T_{a}\right)_{L I}}
$$

Idso et al. (1981) and Jackson et al. (1981) indicated that the values of $\mathrm{T}_{c}-\mathrm{T}_{\mathrm{a}}$ and $\mathrm{e}_{\mathrm{s}}$ $-\mathrm{e}_{\mathrm{a}}$ are linearly related for well-irrigated plants transpiring at potential rate during the daylight hours. As soil moisture is depleted, the $\mathrm{T}_{\mathrm{c}}-\mathrm{T}_{\mathrm{a}}$ versus $\mathrm{e}_{\mathrm{s}}-\mathrm{e}_{\mathrm{a}}$ relationship deviates from the lower limit (non-stressed) of the $\mathrm{T}_{c}$ $-\mathrm{T}_{\mathrm{a}}$ condition, thus, the CWSI increases. The lower limit (LL) represents the maximum rate of transpiration of a well-watered crop and the upper limit (UL) represents the $\mathrm{T}_{\mathrm{c}}-\mathrm{T}_{\mathrm{a}}$ of a canopy with no transpiration and for which the canopy temperature does not respond to $\mathrm{e}_{\mathrm{s}}-\mathrm{e}_{\mathrm{a}}$. The CWSI varies from 0 to 1 with 1 representing a plant having no transpiration loss and 0 representing a plant transpiring at the maximum rate.

The objectives of this research were to 1) analyze growth parameters (GI, growth rates, number of branches in each plant, and shoot and root dry weights) of the plants grown in the white and black MPBSs and CS, 2) quantify and analyze plant stress parameters $\left(r_{s}, C W S I\right.$, PWP, and ST) and elaborate on performance of the white MPBS compared to the black MPBS and CS, and 3) make practical suggestions to the growers/users on the selection of which color MPBS would be more feasible to use under north-central Florida climate conditions.

\section{MATERIALS AND METHODS}

\section{MPBS description}

The MPBS consisted of two sections (lower and upper) made of fiberglass and painted black for UV protection (Figs. 1A and B and $2 \mathrm{~A}$ and $\mathrm{B}$ ). The surface area of the system was $0.787 \mathrm{~m}^{2}(0.82 \times 0.96 \mathrm{~m})$. These dimensions were selected so that the systems could be placed end-to-end in beds to form a continuous surface. Walkways were interspersed for plant maintenance similar to a normal nursery operation. The lower section (reservoir) had four longitudinal channels (about 0.106-m high) that formed water reservoirs with three ridges, sized so that the system can be moved by placing forklift tongues under the outer ridges. Each ridge surface was covered with polyester fabric (Knowlton Nonwovens East Inc., Troy, N.H.) to serve as the wicking material (capillary mat) and allow plants to draw water upward by capillary action. Thus, water in the substrate was replaced by capillarity as needed. Some of the hydraulics and physical characteristics of the capillary mat are as follow: the capillary mat is constructed of $100 \% 0.118$-mm virgin polyester staple fiber. It has a nominal basis weight of $127.5 \mathrm{~g} \cdot \mathrm{m}^{-2}$, a nominal thickness of $3.43 \mathrm{~mm}$ and a nominal density of 0.737 g $1.64 \times 10^{-5} \mathrm{~m}^{-3}$. When fully saturated in water and mechanically wrung out to a damp condition, the capillary mat will retain approximately three times its weight in water (Irmak, 2002). The upper section of the MPBS ( $0.35 \mathrm{~m}$ high) supported the containers and minimized the evaporation losses from the reservoir. Also, it was assumed that the upper section of the MPBS would help to moderate the substrate temperature and plant root zone against extreme temperatures and sudden temperature fluctuations. The surface of the upper section was concave around each container opening to capture rain and irrigation water (Figs. 1 A and B and 2A and B). Thus, water first drains into the container and eventually drains into the reservoir. The lower section (reservoir) stored the captured water until used by the plants. Each box holds nine plastic standard containers [(C-650 The Lerio Corp., El Campo, Texas) with a volume, height, and diameter of $3.8 \mathrm{~L}, 0.17$ $\mathrm{m}$, and $0.15 \mathrm{~m}$, respectively]. The same type of container was used in the MPBS and CS treatments. The only difference is that the containers placed in the MPBS were modified by drilling four equally spaced holes $(0.013$ $\mathrm{m}$ in diameter) through the bottom of the containers to enable the substrate to contact the wicking material for adequate water absorption. Containers were set directly on the ridges in the MPBS. 

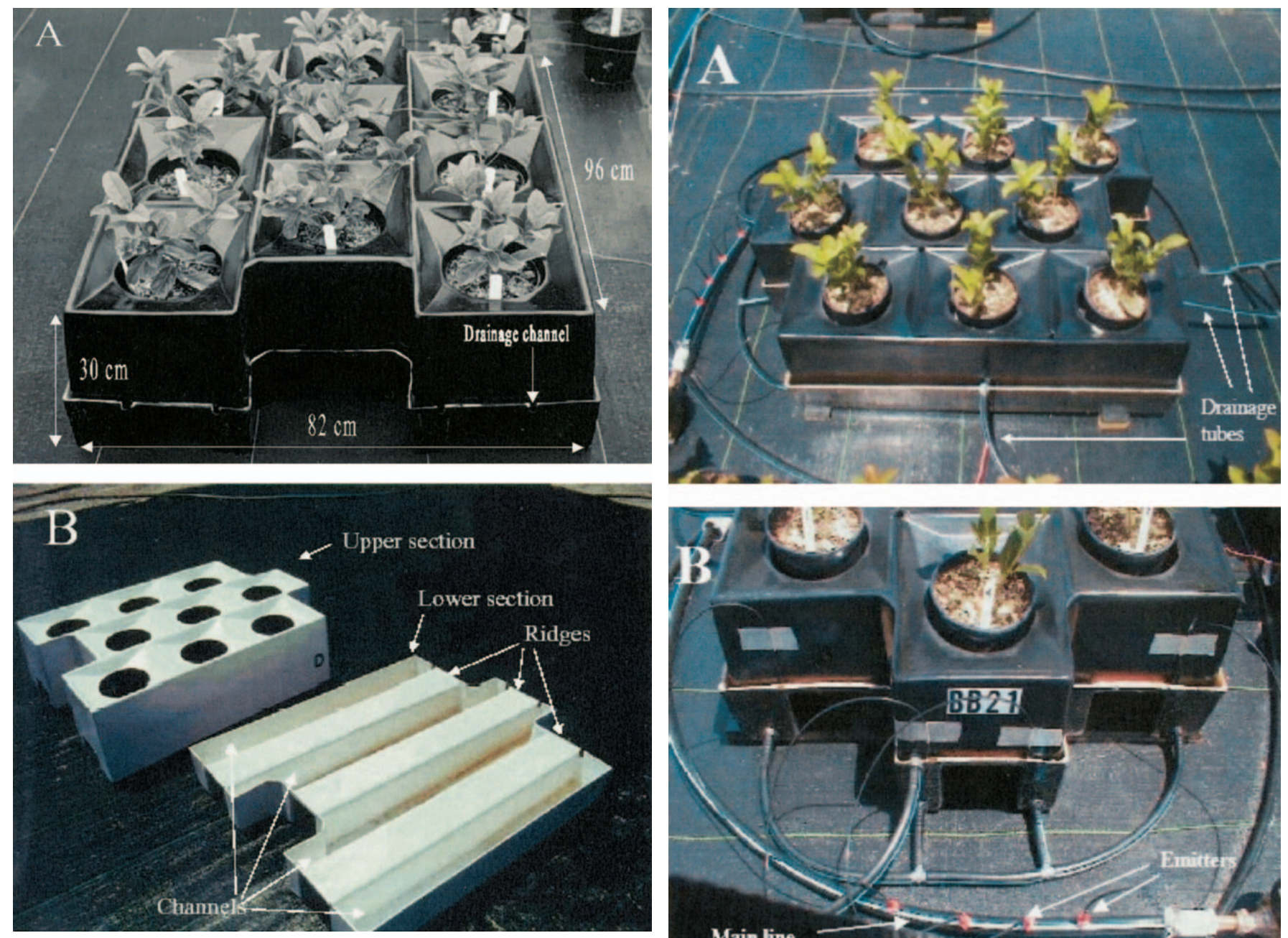

Fig. 1. Original black multiple-pot box system (MPBS) containing nine standard plastic containers (A) and components of a white MPBS placed on the polyethylene groundcover $(\mathbf{B})$.

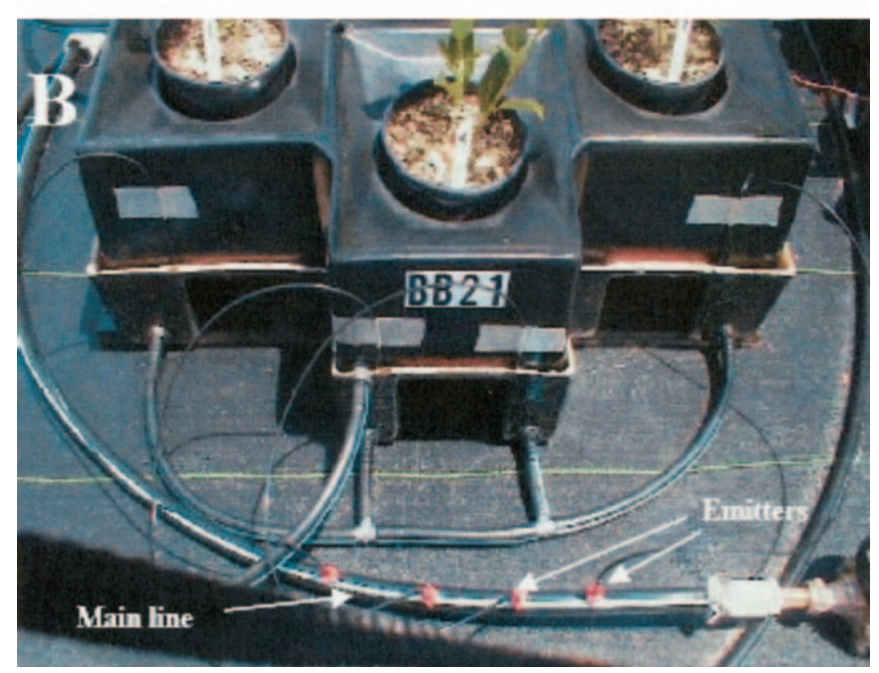

Fig. 2. Modified multiple-pot box system (MPBS) components. Drainage tubes (A) and emitters on the main line (B).

\section{Modifications of the MPBS for} experimental purposes

In the original MPBS the channels in the reservoir were not connected to enable a uniform water level in each channel. In this study, the channels were connected temporar- ily to each other using a $12.7-\mathrm{mm}$-diameter polypipe to create an equal water level in each channel(Fig. 3A). This temporarily prevented the use of a forklift during the experiment. However, for normal nursery practice, connection of the channels is made internally to enable the use of a forklift. A drip irrigation system was used to irrigate the boxes for further water savings. Each channel in the reservoir was equipped with a pressure-compensating drip emitter (Chapin Watermatics Inc., Watertown, N.Y.). The use of pressure
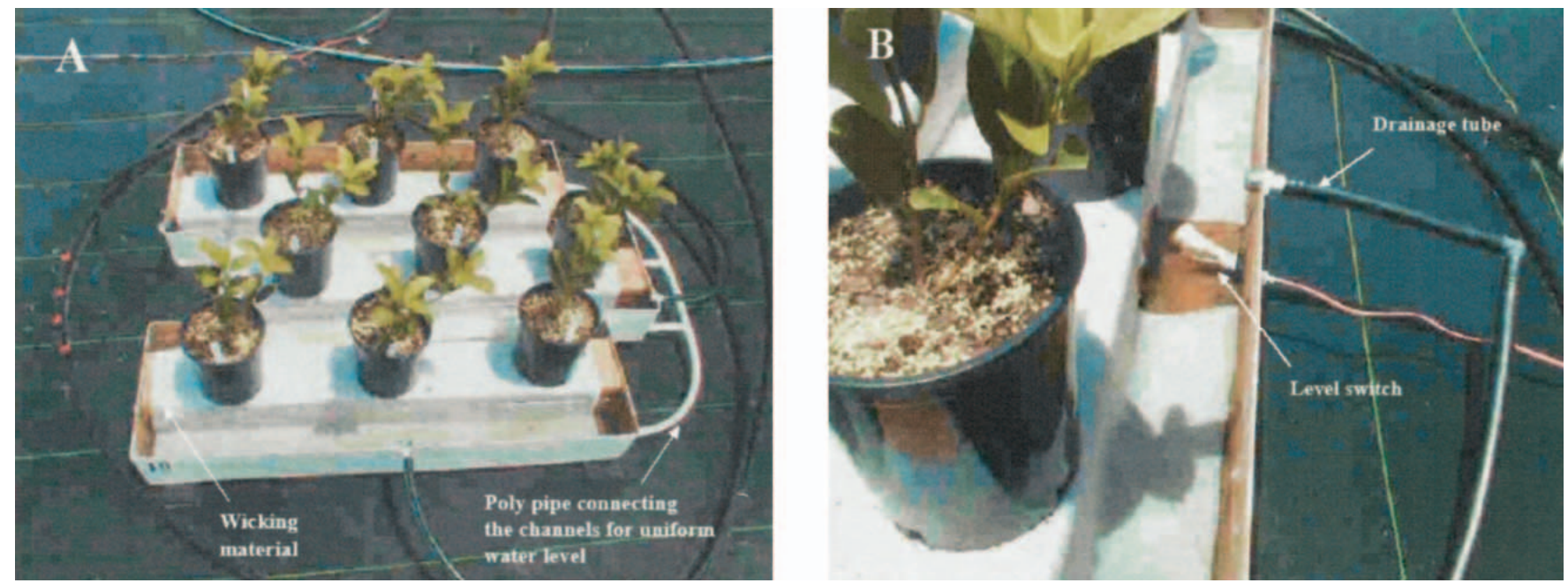

Fig. 3. Polypipe to connect the channels to enable a uniform water level in the reservoir (A) and level switch to control water level and irrigations (B). 
compensating emitters eliminated the effect of slope of the experimental field (there was a $3 \%$ slope in the experimental field) on system pressure. Emitters with a $7.6 \mathrm{~L} \cdot \mathrm{h}^{-1}$ flow rate were installed directly on the mainline (Fig. $2 \mathrm{~A}$ and $\mathrm{B}$ ) and water was delivered to the box using a spaghetti tube and a lead weight placed in each channel. Although the channels were connected in the MPBS, a considerable amount of time lag was observed for water to move from one channel to another to enable an equal water level in each channel. To eliminate this problem, each box had four emitters (one for each channel) with a total of 30.4 $\mathrm{L} \cdot \mathrm{h}^{-1}$ flow rate delivery capacity. However, for normal practice in nurseries, connection pipes are larger in diameter and eliminate this problem. Each box was equipped with a side-mount level switch (model LS-7; State Instruments, Inc., Tampa, Fla.) to trigger the irrigations automatically (Irmak, 2002). Each level switch, placed at a pre-determined depth, was connected to a solenoid valve and an irrigation controller (model ESP-24LX Plus; Rain Bird Co., Tucson, Ariz.). The level switches were installed at 0.01, 0.02, and $0.03 \mathrm{~m}$ from the bottom of the reservoir (depending on the treatment). The level switch triggered irrigation automatically when the water level in the reservoir dropped to about $0.025,0.035$, or $0.045 \mathrm{~m}$ (depending on the treatment). Based on our calculations, $30 \mathrm{~min}$ of irrigation water was needed to be applied to each MPBS in each irrigation. To bypass the level switch when it was closed and enable the irrigation system to run $30 \mathrm{~min}$, each box was also equipped with a $24-\mathrm{V}$ relay (Dayton Elec. Mfg. Co., Niles, Ill.).

\section{Description of the control treatment}

The CS served as the control treatment and represented the irrigation system commonly used by the majority of the nursery growers in Florida. Standard containers in the CS were spaced in three rows $(0.30 \mathrm{~m}$ between the rows and within the rows) apart and were placed directly on separate black polypropylene ground sheeting. The reason of setting the CS containers on a separate ground sheeting was that this treatment was irrigated using overhead sprinklers which is a common irrigation system practiced by the majority of the growers in Florida.

\section{Field experiments}

General experimental procedures. Field experiments were conducted on the campus of the University of Florida, Gainesville (latitude $29^{\circ} 38^{\prime}$, longitude $82^{\circ} 22^{\prime}$, elevation $29.3 \mathrm{~m}$ ) in Summer and Fall 2001. Unless noted otherwise, the experimental procedures were the same for the two growing seasons. Viburnum odoratissimum, Ker-Gawl. ('Viburnaceae') was grown in the standard containers. This plant specie is being grown extensively as a nursery plant throughout the southeastern U.S. Seven treatments were imposed: 1 ) white color MPBS with level switches installed at $0.01,0.02$, and $0.03 \mathrm{~m}$ (W1, W2, and W3) from the bottom of the reservoir (the water levels were controlled at $0.025,0.035$, and
$0.045 \mathrm{~m}$ from the bottom of the reservoir for each treatment, respectively); 2) black color MPBS with level switches installed at 0.01, 0.02 , and $0.03 \mathrm{~m} \mathrm{(B1,} \mathrm{B2,} \mathrm{and} \mathrm{B3);} \mathrm{and} \mathrm{3)}$ control treatment $(\mathrm{CS})$.

The treatments were laid out as a randomized complete block and replicated three times, with the exception of the CS. The CS was replicated six times. There were nine plants in each replication. When the plants in the MPBS treatments reached marketable size, the experiment was terminated. However, at that time, plants in the CS were not at marketable size. Therefore, an additional three replications in the CS were used to monitor plant growth and to determine the dry matter when the CS plants were marketable size.

In all treatments, black \#1, 3.8-L plastic containers were used. Containers were filled with a substrate containing 2 pine bark : 1 Canadian peat $: 1$ sand (by volume), amended with $4.2 \mathrm{~kg} \cdot \mathrm{m}^{-3}$ of dolomitic James River Limestone and $0.9 \mathrm{~kg} \cdot \mathrm{m}^{-3}$ of Micromax (Scotts Co., Marysville, Ohio) and placed in each MPBS. The same substrate was used for the containers in the CS. Healthy and uniform size plants were transplanted into substratefilled containers and grown for 3 to 4 weeks in a shade-house (30\% shade). During the shading, plants were hand-watered as needed. Four hundred sixty milligrams per container of liquid fertilizer (300 ppm of nitrate) was applied to each pot before experiments began. Plants were top dressed with $0.014 \mathrm{~kg} /$ container of Osmocote 18N-2.6P-9.7K (18-6-12) controlled (slow-release) fertilizer (Scotts Co.) at the beginning of each experiment. Experiment starting and termination dates for the summer and fall, respectively, were 17 May 2001 to 9 Aug. 2001; and 28 Aug. 2001 to 21 Dec. 2001. Experiments were terminated when the plants grown in the MPBS treatments reached approximately a marketable size based on the Florida Grades and Standards (Anonymous, 1997) at the grade of Florida Fancy for 3.8- to 7.6-L containers. At termination, plants grown in the CS were not at a marketable size. So, three sets of the CS plants were harvested and measurements, including plant growth, were continued using the second set of CS plants until the plants reached marketable size. Thus, at termination, half of the CS (3 replications, 27 plants) was terminated for statistical analyses. At termination, shoots of all plants were severed above the uppermost roots, the roots were cleaned from the substrate, and shoot and root dry weights were determined after drying to a constant weight at $70{ }^{\circ} \mathrm{C}$. Shoot and root dry weights and other responses to treatments were analyzed by analysis of variance (ANOVA). When ANOVA identified treatment effects, Duncan's multiple range test (DMRT) was used to identify which treatments differed at the 5\% significance level.

Irrigation applications. The irrigated area of the CS was $6.0 \times 6.0 \mathrm{~m}$. The CS plot was irrigated with four rotary drive sprinkler heads (PGM-04-A, Hunter Industries, San Marcos, Calif.) mounted on 1.3-m risers and located at the corners of the plot. The coefficient of uniformity, determined using the catchcan test, for sprinkler irrigation system, $\mathrm{C}_{\mathrm{u}}$, (Christiansen, 1942) was $94 \%$. Water was applied daily for an hour with an irrigation application rate of 18 $\mathrm{mm} \cdot \mathrm{h}^{-1}$. This was the normal application rate that is being practiced by the majority of the growers in Florida. Sprinkler application was also measured with a positive displacement type precision flowmeter (model C-700; ABB Water Meters, Inc, Ocala, Fla.) to verify the total amount applied. Irrigations were not scheduled and a fixed amount of irrigation water was applied to the CS treatment in each irrigation. The main objective of not scheduling irrigations in the CS was that this treatment was treated as close to the normal practice as possible.

Irrigations were applied to MPBSs whenever the reservoir in the bottom of the boxes receded to $0.025,0.035$, and $0.045 \mathrm{~m}$, depending on the treatment. Irrigation was applied for $30 \mathrm{~min}$ to deliver about $16 \mathrm{~L}(20 \mathrm{~mm}$, based on the surface area of the box) of water. The main purpose of not irrigating the boxes to the full reservoir capacity $(0.106 \mathrm{~m})$ was to keep a part of the reservoir empty to provide storage for the rainwater. The $\mathrm{C}_{\mathrm{u}}$ value (determined using the catchcan test) of the drip irrigation system used in MPBS was $97 \%$. Although the channels in the MPBS were connected, small differences were observed in water levels in individual channels. This was due to the $3 \%$ slope in the experimental plot that made it difficult to have a perfect leveling of the boxes. Therefore, four water level measurements (one from each channel) in each box were taken and averaged. The water level in the MPBS reservoir was recorded on a daily basis by placing a scaled wood dowel vertically through a hole opened in the box surface to quantify the amount of rainwater captured in the MPBS. A rain sensor was installed to shut off the irrigations when about $12.7 \mathrm{~mm}$ rain occurred. Rainfall was recorded using a rain gauge at the experimental site.

\section{Measurement of plant growth and stress parameters}

Growth index. The GI can be used as a quantitative indicator of plant growth rate and to compare the size of the plants grown under different systems. In this study, the plants were considered at marketable size when they reach GI value of 40 . The plant heights, by measuring from the substrate surface to the tip of the tallest leaf, were taken on selected dates. On the same day, plant widths were measured in both east-west (parallel to the plant rows) and north-south (perpendicular to the plant rows) directions. In plant width measurements, the distance between the most outer two leaves was measured. In the summer and fall growing seasons, six growth measurements (height and width) were taken from the plants grown in the white and black MPBSs. Eleven and nine growth measurements were taken from the control treatment in the summer and fall seasons, respectively. All plants were measured in all replications. Thus, a total of 189 plants were measured in each sampling date. GIs for each plant were calculated as

$\mathrm{GI}=\mathrm{H}+((\mathrm{WEW}+\mathrm{WNS}) / 2) / 2$

where $\mathrm{H}$ is the plant height $(\mathrm{m})$, WEW is the canopy width in east-west direction (m), 
and WNS is the canopy width in north-south direction $(\mathrm{m})$.

Crop water stress index. To determine the CWSI, several weather parameters needed to be measured. An automated weather station was set about $30 \mathrm{~m}$ from the experimental site. The

grass around the weather station was irrigated as needed and clipped to provide reference conditions (Allen et al.,1994a, 1994b). The data collected at the weather station included air temperature, relative humidity, incoming solar radiation, wind speed at 2-m, and rainfall. All
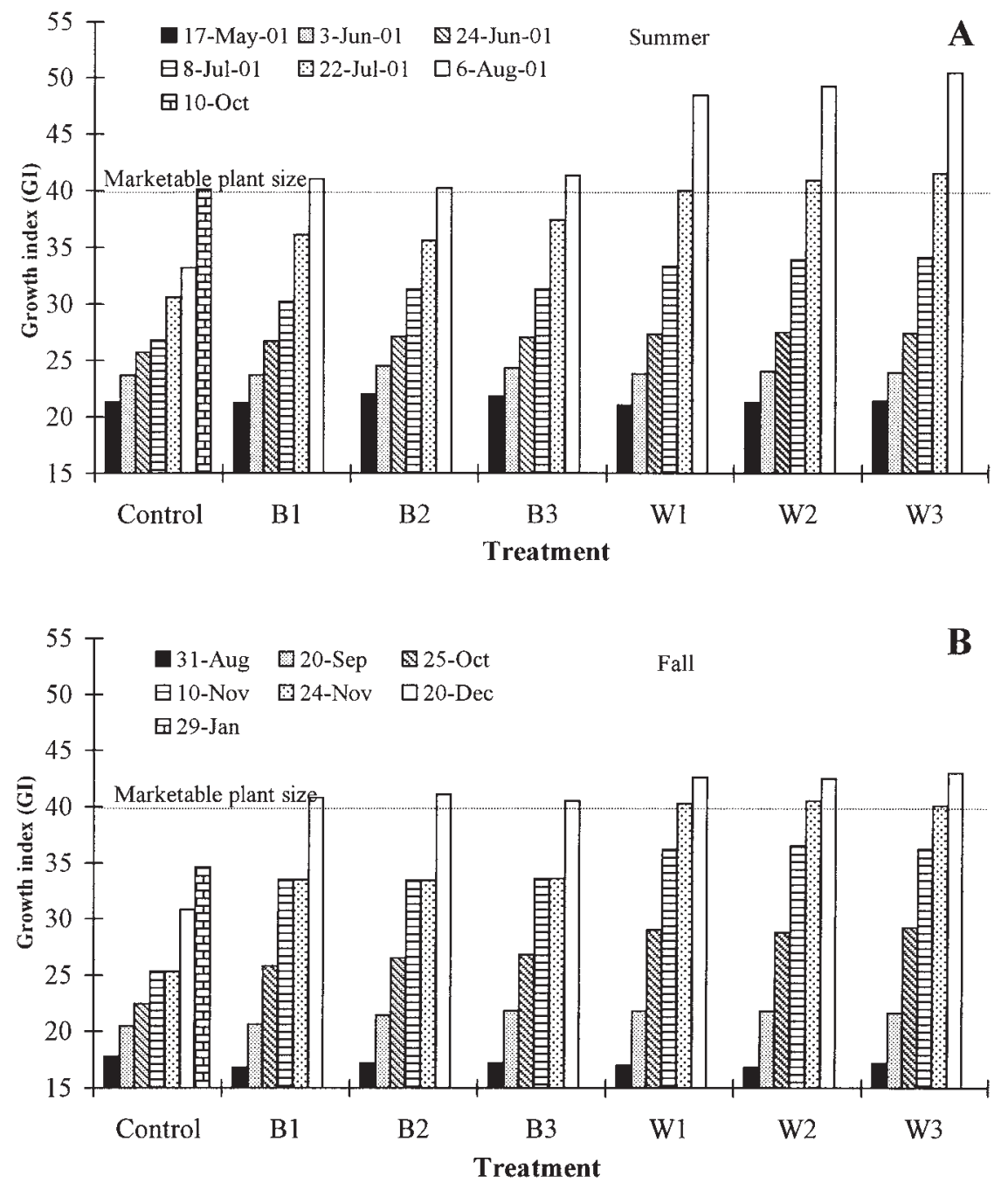

Fig. 4. Growth index (GI) throughout the summer (A) and fall (B) seasons. B and W = black and white multiple-pot box system (MPBS) treatments, respectively. The numbers 1, 2, and 3, represent the depths at which the level switches were installed $(0.01,0.02$, and $0.03 \mathrm{~m}$ from the bottom of the system reservoir).

Table 1. Statistical analyses of the growth index (GI) at harvest, number of stem in each plant, stem and root dry weights of the plants grown in the white and black multiple-pot box systems (MPBSs) and control treatments (CS) in the summer and fall growing seasons.

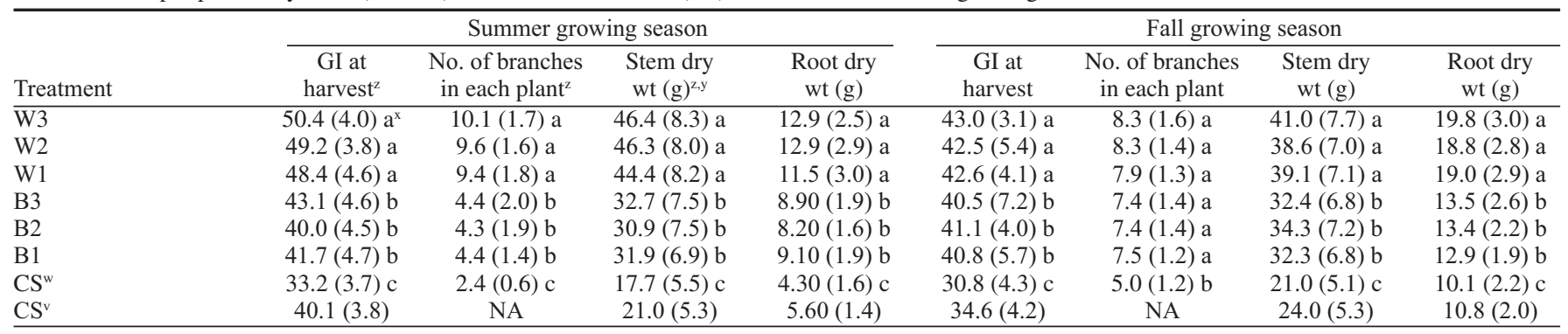

${ }^{\mathrm{z}}$ Average of 27 plants from 3 replications (9 plants in each replication).

${ }^{y}$ Values in parenthesis indicate standard deviations.

'Means followed by different letters among the treatments are significantly different at the $5 \%$ significance level as indicated by Duncan's multiple range test. wDry weights, GI, and number of stems of the plants in control treatment harvested whenever the plants grown in the MPBS reached marketable size based on the Florida Grades and Standards (Anonymous, 1997) at the grade of Florida Fancy for 3.8- to 7.6-L containers category.

'Dry weights, GI, and number of stems of the plants in the second sets of the replication ( 3 replications, 27 plants). Since the plants in the control treatment were not at marketable size when the plants grown in the MPBSs were harvested, measurements were still being taken from the second sets of the replication in the control treatment until the plants reached marketable size.

"NA = not available.
To calculate CWSI values using Eqs. 4 through 7, the values of $\Delta, \mathrm{R}_{\mathrm{n}}, \mathrm{e}$, and e were calculated using equations $13 ; 21,37,38,39$, and 40 for $\alpha=0.23$; and 11,12 , respectively, as outlined in the Food and Agriculture OrgaPaper No. 56 (Allen et al., 1998). The dynamic resistance ( $r$ ) and Stefan-Boltzmann constant for the calculation of the net outgoing longwave radiation $\left(\mathrm{R}_{\mathrm{n1}}\right)$ were taken as 0.41 and $4.903 \times 10^{-9} \mathrm{MJ} \cdot \mathrm{K}^{-4} \cdot \mathrm{m}^{-2} \cdot \mathrm{d}^{-1}$, respectively. For the values of zero plane displacement height (d) and roughness length governing momentum transfer $\left(\mathrm{z}_{\mathrm{om}}\right)$ in the calculation of $\mathrm{r}_{\mathrm{a}}$, the plant height (h) measurements that were taken on the same day as $r_{s}$ measurements were used, A value of $1.013 \times 10^{-3} \mathrm{MJ} \cdot \mathrm{kg}^{-1} \cdot{ }^{\circ} \mathrm{C}^{-1}$, which represents an average value of specific heat at constant pressure (c ), was used in the calculations. The latent heat of vaporization was taken as $2.45 \mathrm{MJ} \cdot \mathrm{kg}^{-1}$.

Stomatal resistance $\left(r_{s}\right)$ measurements. The $\mathrm{r}_{\mathrm{s}}$ measurements in both seasons were taken using a steady-state porometer (model AP4; selected days when clear sky conditions were observed. The CWSI values for each treatment (W2, B2, and CS) were determined on an hourly basis to observe the diurnal pattern of the CWSI the $r$ given treatment. Therefore, in summer, to 7 PM every hour on 21 and 25 July. In fall, the hourly $r_{s}$ measurements were taken from 7 AM to 7 PM on 20 Sept., and from 9 AM to 5 $20 \mathrm{Dec}$. The number of measurements days due to the shorter daytime hours in the winter. The $r$ measurements were taken from three leaves (by taking five readings from each leaf) and from seven plants in each treatment to obtain a good indication of the plant stress for a given treatment. Thus, 105 measurements taken for each treatment and averaged for every hour. The measurements were taken from the same leaf each hour. The porometer was calibrated based on the manufacturer's recommendations before the measurements. 

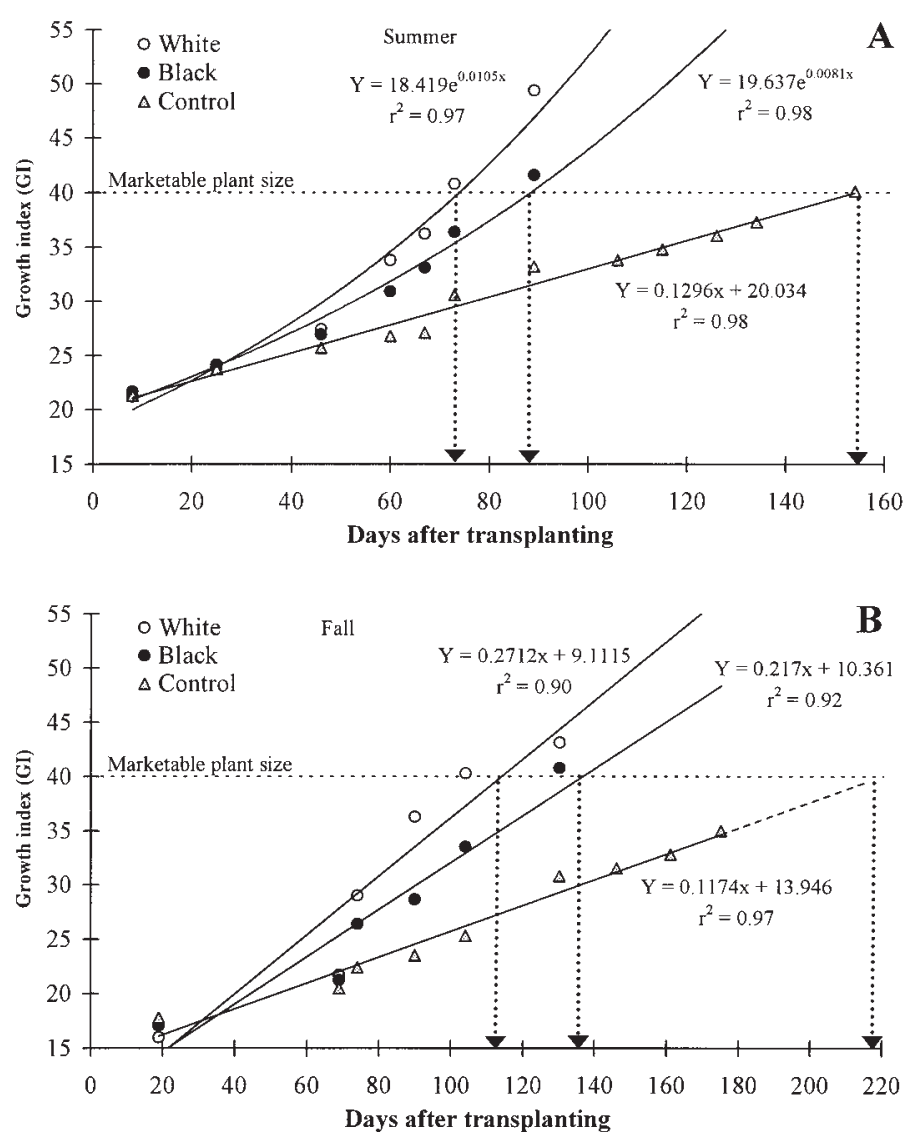

Fig. 5. Quantification of growth rates of plants grown in the white and black multiple-pot box system (MPBS) and conventional system (CS) treatments in the summer (A) and fall (B) growing seasons.
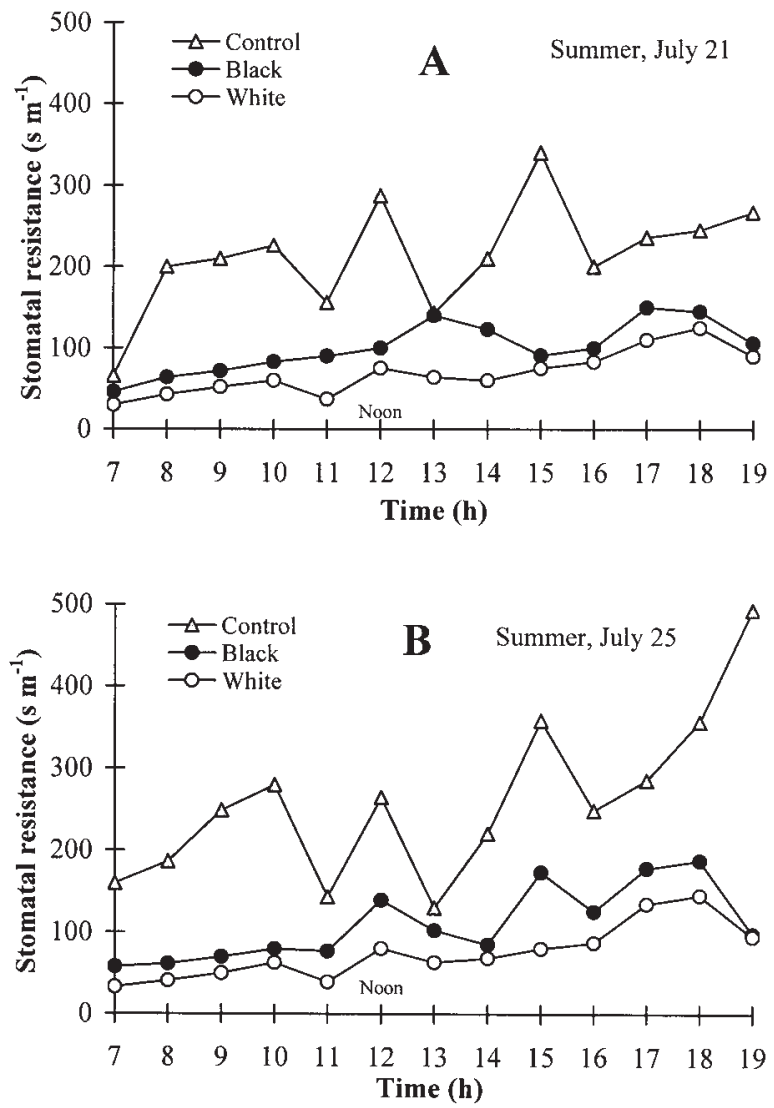

Fig. 6. Diurnal pattern of stomatal resistance of plants on 21 July (A) and 25 July $(\mathbf{B})$ in the summer growing season.
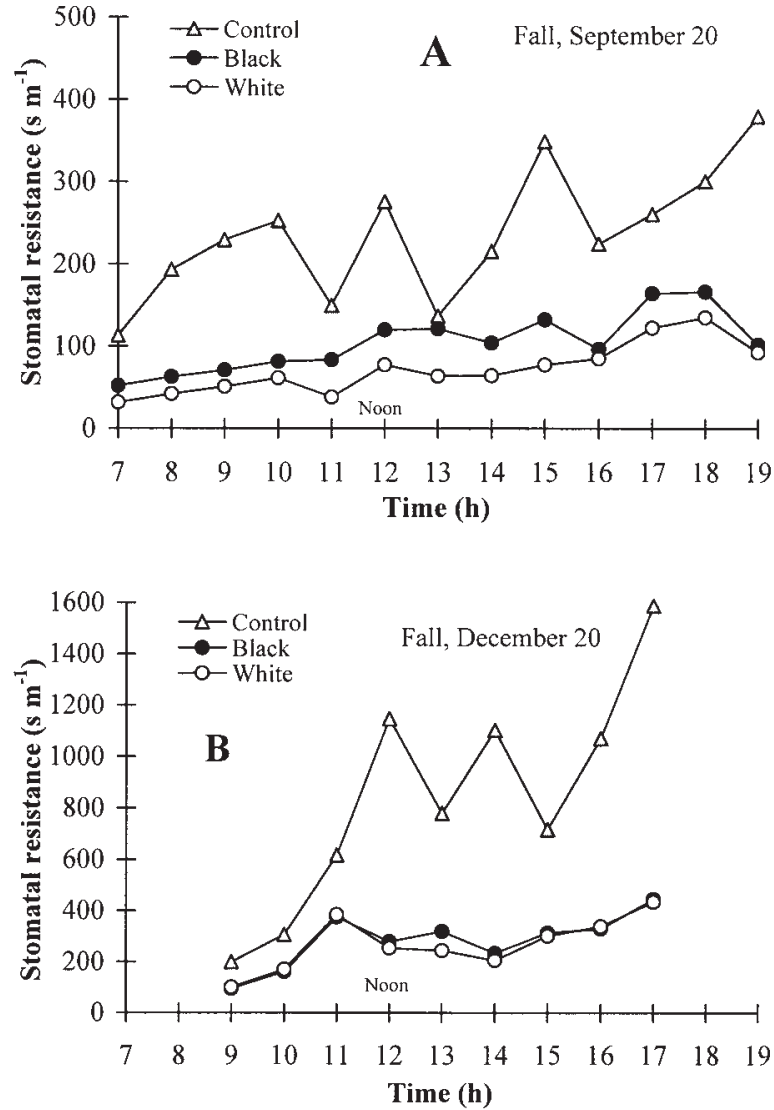

ig. 7. Diurnal pattern of stomatal resistance of plants on 20 Sept. (A) and 20 Dec. (B) in the fall. 
tion in the W2, B2, and CS treatments was equipped with thermocouples for substrate temperature measurements. Copper-constan$\tan (0.0005 \mathrm{~m}$ in diameter $)$ thermocouples were placed at middle depth (about $0.08 \mathrm{~m}$ from the bottom of the container) in the center of each container and substrate was hand packed to enable adequate contact with the thermocouples. An additional thermocouple was placed at $1 \mathrm{~m}$ height above ground in the middle of the experimental plot to measure ambient air temperature. Thermocouples were connected to the data acquisition systems and measurements were recorded using a datalogger and a multiplexer (model CR-10 and model $32 \mathrm{M}$, respectively, Campbell Scientific Inc., Logan, Utah).

\section{RESULTS AND DISCUSSION}

Growth Indices. The amount of rainfall, daily water level fluctuations in the reservoirs, and the total amount of irrigation water applied to each treatment were reported by Irmak et al. (2003). The GIs of plants in the white and black MPBSs (W2 and B2) and CS throughout the summer and fall growing seasons, respectively, are given in Figs. 4A and B. Other plant growth parameters, including stem and root dry weights at harvest, are also included in Table 1 for comparison. The GI values were calculated as an average of three replications (nine plants in each replication) for each treatment. Figure 4A shows that plants grown in the white MPBS treatments reached marketable size earlier as compared to plants in the black MPBS and CS treatments. In summer, the final GI values of the plants in all white MPBS treatments were significantly greater than those of plants in the black MPBS and control plants (Table $1)$. Note that at the time when plants in the MPBSs were harvested (9 Aug. 2001), the CS plants were not at marketable size. However, growth measurements continued to be taken from the plants in the second sets of replication until they reached marketable size on 10 Oct. 2001 (Fig. 4A).

The number of branches in each plant was counted before harvest and treatment-averaged values are reported in Table 1 . The plants grown in the white MPBS had significantly higher number of stems compared to the other treatments in summer. None of the growth parameters of the plants within the white or black MPBS treatments were significantly different $(p>0.05)$. In fall, plants in the black and white MPBSs had more stems $(p<0.05)$ than plants in the CS (Table 1). Figure 4B shows that plants in the white MPBS treatments reached marketable size earlier than those grown in the black MPBSs and CS.

Although Fig. 4A and B can provide useful information on the change in plant size and the date when plants reached marketable size, they do not provide quantitative information on the growth rate of the plants grown under different treatments. In Fig. 5A and B, the GI values are graphed as a function of days after transplanting (DAT, X-axis) for the summer and fall seasons, respectively, showing the differences in plant growth rates between the treatments. Figure 5A indicates that, in the summer, plants in the white and black MPBSs had an exponential growth rate with plants grown in the white MPBS having significantly greater growth rate (greater slope) compared to the plants in the other treatments.

Figure $5 \mathrm{~A}$ and $\mathrm{B}$ allowed us to determine the number of days required for the plants to reach marketable size $(\mathrm{GI}=40)$. Data indicated that the white MPBS plants reached marketable size about $70 \mathrm{~d}$ after transplanting (DAT) whereas the black MPBS plants reached marketable size 87 DAT, and the CS plants reached marketable size 156 DAT in the summer. Thus, plants in the white MPBS reached marketable size 17 days, and $86 \mathrm{~d}$ earlier than those in the black MPBS and CS, respectively.

Figure 5B showed that, in the fall growing season, all treatments had a linear growth rate with plants in the white MPBS having a higher growth rate than the other two treatments. The growth rates were slower in the fall then in the summer. The slower rates were attributed to the shorter day length, lower temperature, and lower solar radiation as compared to the summer.

Figure 5B indicates that the white MPBS plants reached marketable size approximately 103 DAT whereas the black MPBS plants reached marketable size 128 DAT, and plants in the CS never reached marketable size dur-
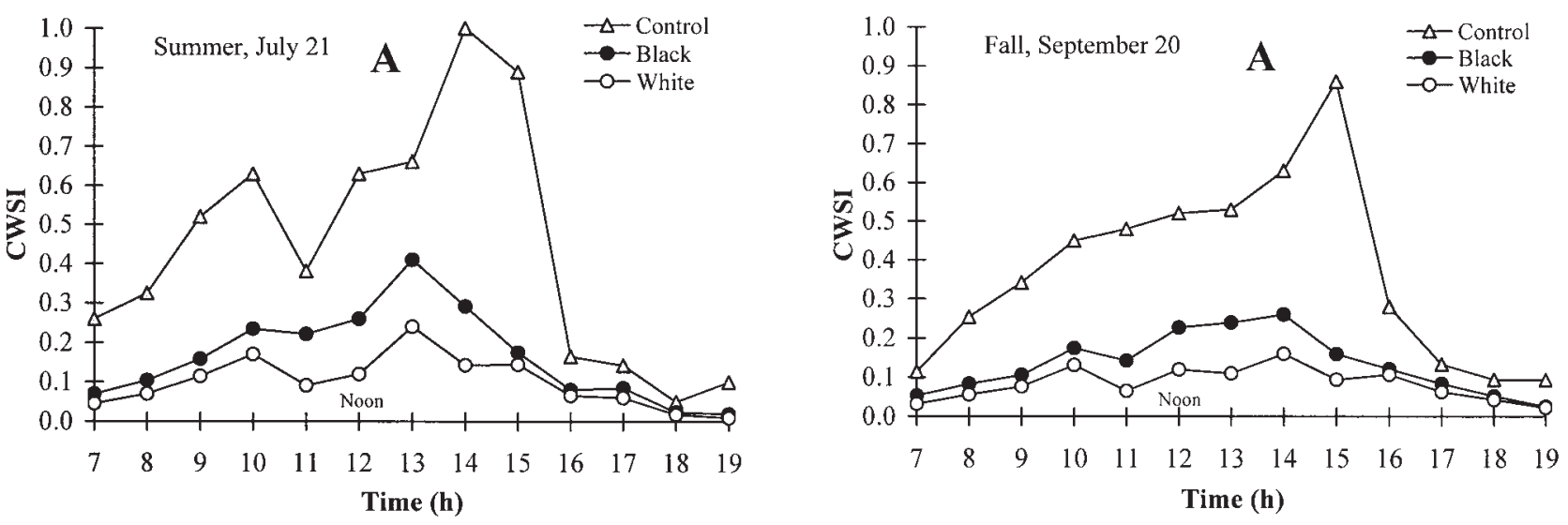

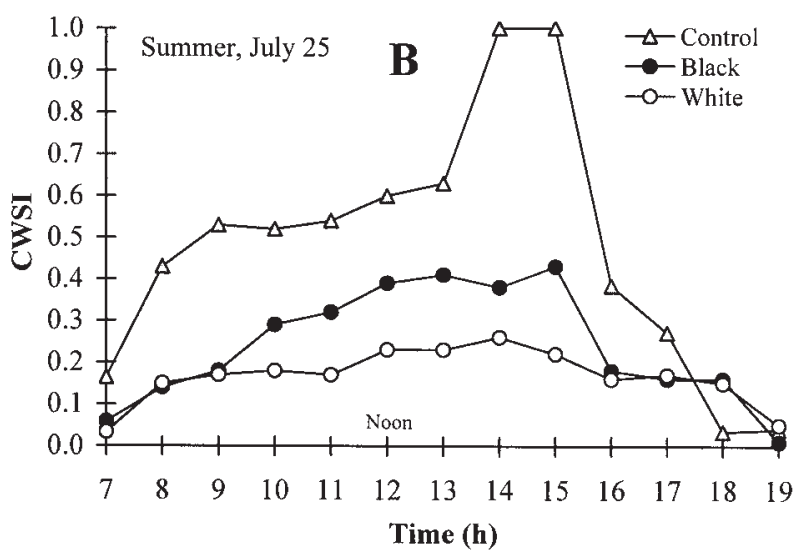

Fig. 8. Diurnal pattern of crop water stress index (CWSI) on 21 July (A) and 25 July (B) in the summer growing season.

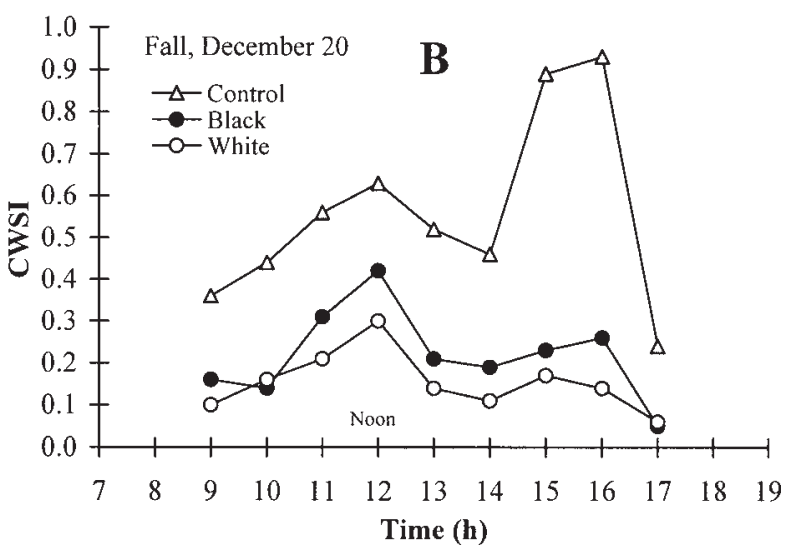

Fig. 9. Diurnal pattern of crop water stress index (CWSI) on 20 Sept. (A) and 20 Dec. (B) in the fall season. 
ing the period of the experiment. However, the measurements had been continued to be taken from the CS plants until 29 Jan., and after this day, the experiment was terminated. Therefore, the number of days that the CS plants reach marketable size was estimated. Since the regression line of CS did not intercept with the marketable plant size line in Fig. 5B, the regression line was extended starting from about day 175 and intercepted to the marketable plant size line. Based on the estimates, the CS plants reached marketable size 115 DAT.

Diurnal pattern of stomatal resistance. As mentioned before, all $r_{s}$ measurements were made under clear sky conditions. Maximum air temperatures ranged from 22.4 to $36.8{ }^{\circ} \mathrm{C}$ on 21 July; from 22.6 to $38.9^{\circ} \mathrm{C}$ on 25 July; from 21.7 to $36.2^{\circ} \mathrm{C}$ on $20 \mathrm{Sept}$; and from 7.4 to $22.0^{\circ} \mathrm{C}$ on $20 \mathrm{Dec}$. during the course of the measurements. The average wind speed on the day of measurements showed some variations. The average wind speed on 21 July, 25 July, 20 Sept., and 20 Dec., respectively, were 2.2, $3.3,1.1$, and $3.2 \mathrm{~m} \cdot \mathrm{s}^{-1}$.

Diurnal patterns of $r_{s}$ measurements for summer and fall seasons, respectively, are given in Figs. 6A and $\mathrm{B}$ and $7 \mathrm{~A}$ and $\mathrm{B}$. The $r$ showed variations during the day. In all measurements dates, with the exception of the 20 Dec. measurements, the plants in the white MPBS had significantly lower stomatal resistance to vapor transport compared to the other two treatments. Plants in the black MPBS had significantly lower $r_{s}$ values compared to the plants in the CS. On 20 Dec., the $r_{s}$ values of the plants in the white and black MPBS were not significantly different. Results suggest that the number of stomata that were opened at any given time for the plants in the white MPBS were greater compared to those of plants grown in other treatments causing less resistance to the water vapor transport and, thus, higher photosynthesis and transpiration rate and less plant stress. Generally, the $r_{s}$ values were found to be lowest in the morning hours and increased as the air temperature increased. For example, the $r_{s}$ values were lowest for the plants grown in the white and black MPBS, and CS and they were $30,46,60 \mathrm{~s} \cdot \mathrm{m}^{-1}$, respectively, at 7 AM on 21 July (Fig. 6A). Similar patterns, with different $r$ values, were observed on the other sampling dates. Although the time of the day with the highest $r_{s}$ varied among the CS and MPBS treatments, they were usually similar for the white and black MPBS treatments. For example, the highest $r_{s}$ value of the plants in the white and black MPBS treatments was usually observed in the late afternoon hours.

The plants grown in all treatments had considerably higher $r_{s}$ values on 20 Dec. compared to those obtained in other sampling dates. This might be due to the lower air temperatures on 20 Dec. Kramer (1983) reported that at low temperatures, plant responses to light and humidity are slower, and stomatal resistances are usually higher. Daily maximum air temperature ranged from low 20 s to high 30 s on 21 July, 25 July, and 20 Sept. whereas it was much lower and ranged from 7.4 to $21.8^{\circ} \mathrm{C}$ on 20 Dec. Under ideal and constant (hypothetical) conditions, one can assume that the $r_{s}$ to the water vapor transport of a crop which is well-watered, disease free, actively growing, and transpiring at potential rate should have lower $r_{s}$ values than those given in Figs. 6A and $\mathrm{B}$ and $7 \mathrm{~A}$ and $\mathrm{B}$ since the $\mathrm{r}_{\mathrm{s}}$ measurements of the plants grown in the MPBS treatments were taken under well-watered, actively growing, and disease free conditions. This is expected because while all these conditions/variables are assumed to be constant, hourly $r_{s}$ measurements occur under highly variable conditions. Also, stomatal activity is affected not only by the water availability to the plants, but it is also affected by numerous internal and external factors, including, leaf water status, leaf temperature, substrate and irrigation water temperature, solar radiation, wind speed, humidity, internal and external $\mathrm{CO}_{2}$ concentration, growth regulators, and more importantly interactions of these factors which are challenging to determine.

Crop water stress index. The hourly CWSI values that were calculated using hourly $r_{s}$ measurements, $\mathrm{T}_{\mathrm{c}}-\mathrm{T}_{\mathrm{a}}$, and upper and lower limits, UL and LL, (Eqs. 4 through 7) on 21 July, 25 July, 20 Sept., and 20 Dec. are shown in Figs. 8A and B, and 9A and B, respectively. On the day of measurements, plants in the white and black MPBS were assumed to have no water limiting conditions since the water level in the reservoir of each MPBS was never
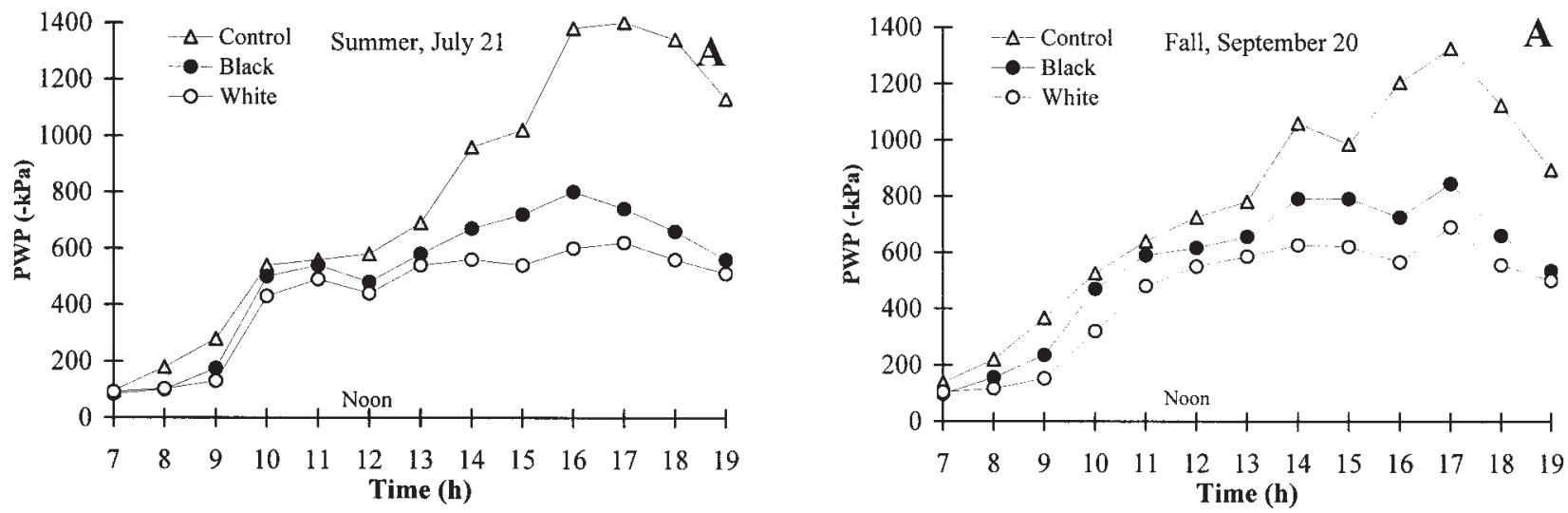

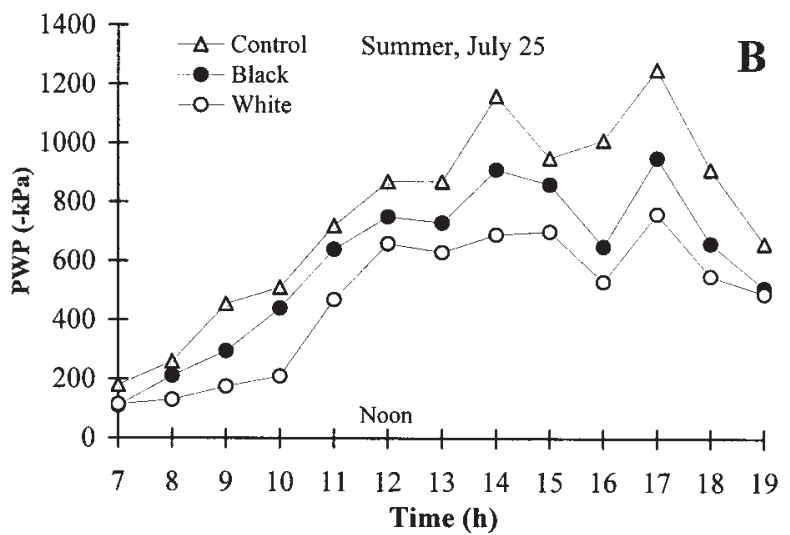

Fig. 10. Diurnal pattern of plant water potential (PWP) on 21 July (A) and 25 July $(\mathbf{B})$ in the summer season. Each data point represents an average of three measurements.

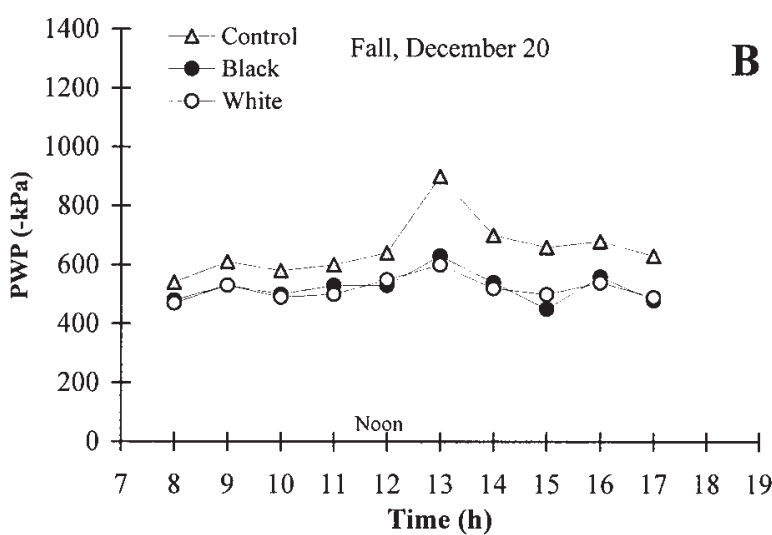

Fig. 11. Diurnal pattern of plant water potential (PWP) on 20 Sept. (A) and 20 Dec. (B) in the fall season. Each data point represents an average of three measurements. 
dropped below $0.01 \mathrm{~m}$. Results of four hourly measurements were similar for four sampling dates with plants in the white MPBS having the lowest CWSI values among the treatments at all times. The CWSI values in the white and black MPBSs were not significantly different. However, the CWSI values of the plants in both white and black MPBSs were significantly lower than the values in the CS. Thus, plants grown in the white MPBS experienced less stress.

The general pattern of the hourly CWSI in all treatments were similar with the lowest CWSI occurring in the early morning hours and increasing with time during the day, and decreasing again in the late afternoon hours. It has been reported (Idso, 1982; Idso et al., 1981; Jackson, 1982; Jackson et al., 1981; Reginato, 1983) that for many agronomic crops, the maximum CWSI (CWSI max $_{\text {) usually }}$ occur between 12 and 2 PM. The CWSI max $_{\text {in }}$ this study usually occurred between 2 and 4 PM for the CS treatment and between 12 and 3 PM for the MPBS treatments. Although CWSI $_{\text {max }}$ for all treatments were observed in the afternoon hours, the magnitude of the CWSI $_{\max }$ level showed variations between the treatments, and for the same treatment between the measurements dates. For example, on 21 July, the CWSI ${ }_{\max }$ for the plants in the white and black MPBS occurred at 1 PM as 0.24 and 0.41 , respectively, whereas the CWSI for the CS was 1.0 at 2 PM (Fig. 8A). On 25 July, the CWSI for the plants in the white MPBS occurred at 2 PM (0.26), and was at 3 PM (0.43) for the plants in the black MPBS (Fig. 8B). On the same day, for the plants in the CS, the stress level reached upper limit $(\mathrm{UL}=1.0)$ two times at 2 and 3 PM, indicating that the plants grown in the CS were under severe stress at these times and they were not transpiring water because the canopy temperature ( $\left.\mathrm{T}_{c}\right)$ was not responding to the changes in the vapor pressure deficit of the air $\left(e_{\mathrm{s}}-\mathrm{e}_{\mathrm{a}}\right)$. The CWSI value of 1.0 was also observed on 21 July at 2 PM for the control plants (Fig. 8A). On 20 Sept., the CWSI $_{\max }$ for the CS was 0.86 and observed at 3 PM (Fig. 9A). The least difference in CWSI between the white and black MPBSs was observed on 20 Dec.

The daily average values of the CWSI of the plants in the white MPBS ranged from 0.08 on 20 Sept. to 0.17 on $25 \mathrm{July}$; for the plants in the black MPBS, they ranged from 0.13 on 20 Sept. to 0.24 on $25 \mathrm{July}$; and for the plants grown in the CS it ranged from 0.37 on 20 Sept. to 0.56 on $20 \mathrm{Dec}$. The hourly and daily average CWSI of all treatments was slightly higher on 25 July with the exception of the CS. This might be due to the higher temperature and solar radiation on that day compared to the other sampling dates. Also, as reported earlier, the daily average wind speed on 25 July was higher $\left(3.3 \mathrm{~m} \cdot \mathrm{s}^{-1}\right)$ than those measured on the other sampling dates $\left(2.3 \mathrm{~m} \cdot \mathrm{s}^{-1}\right.$ on 21 July and $1.1 \mathrm{~m} \cdot \mathrm{s}^{-1}$ on $20 \mathrm{Sept}$.). The wind speed effects on stomatal closure and its effect on the degree of plant stress were discussed by Knoerr (1967), Caldwell (1970), Davies et al. (1974), and Kramer (1983).
Each crop has a unique productivity response to water stress. Consequently, the value of maximum allowable CWSI for maximizing yield or dry matter production varies from one crop to another. For many agronomic crops, the maximum allowable CWSI values have been studied. For example, for wheat (Triticum aestivum L.), corn (Zea mays L.), and cotton (Gossypium hirsutum L.) crops the CWSI value can be allowed to increase to 0.2 to 0.3 index units (Gardner et al. 1992) between the irrigations without causing significant economic losses on the yield. There is a lack of research in determining the allowable CWSI $_{\max }$ value that does not cause a significant reduction in plant growth, plant biomass production, and on plant quality (appearance) for nursery plants. However, when the CWSI values are considered, based on the results in Figs. 8 and 9, it can be suggested that allowing Viburnum odoratissimum grown in the white MPBS to experience a max stress level of 0.30 during the growing season would not cause significant reductions in plant growth and dry matter production.

One might question why the CWSI of the plants grown in the MPBSs were not closer to zero since these plants were not under water limiting conditions as there was always an adequate water supply in the reservoir of the MPBS to be used by the plants as needed. This is because there are several other environmental variables (substrate temperature in the container, water temperature in the MPBS reservoir, root-zone temperature, etc.) that can
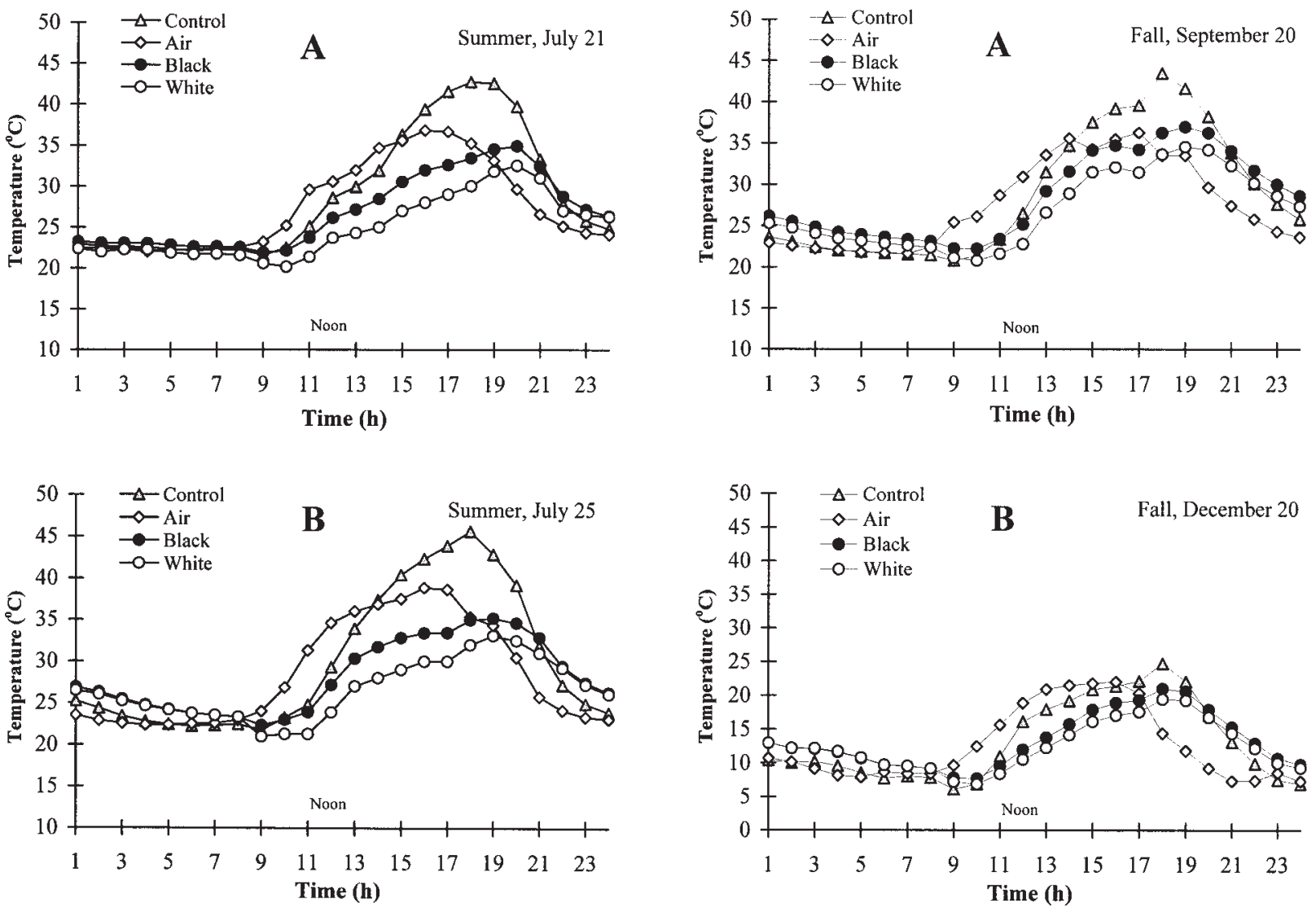

Fig. 12. Diurnal pattern of the substrate temperatures (ST) at $0.09-\mathrm{m}$ from the surface of the container on 21 July (A) and 25 July (B) in the summer season.

Fig. 13. Diurnal pattern of the substrate temperatures (ST) at $0.09-\mathrm{m}$ from the surface of the container on 20 Sept. (A) and 20 Dec. (B) in the fall season. 
affect the root water uptake even if water is not a limiting factor. Also, Jackson (1982) points out that the relationship between CWSI and soil water content (or substrate water content in this case) is not unique, and it is affected greatly by the rooting volume and distribution, stress conditions of the root systems, and evaporative demand. Since precise information on the rooting volume and distribution are not available in this study, the exact correlation of CWSI and soil water content in the substrate should not be expected. Part of the CWSI values of the plants in the MPBSs (especially in the black MPBS) and CS might be associated with the heat-induced stress caused by the high substrate temperatures. Note that the main objective of using CWSI in this study was only to quantify the stress level of plants in response to the treatments. Suggesting the use of CWSI for irrigation scheduling was not the intent of this study because although the CWSI method was proven to be an effective method for scheduling irrigations in arid and semi-arid climates, in humid climates such as Florida, cloud cover in a significant portion of the summer months can be an impediment for this method to be effectively used for scheduling irrigations. However, our results indicated that the method can successfully be used to quantify the stress levels of plants grown under different plant production systems.

Diurnal patterns of plant water potential. The diurnal changes in PWP for each treatment (W2, B2, and CS) on 21 July, 25 July, 20 Sept., and 20 Dec. are presented in Figs. 10A and B and $11 \mathrm{~A}$ and $\mathrm{B}$, respectively. Each data point for each hour represents an average of three measurements for each treatment. Generally, plants in the white MPBS showed higher (wetter) PWP values compared to the plants in other treatments in all sampling dates, with the exception of the 20 Dec. measurements. On 20 Dec., the white and black MPBS resulted in almost identical PWP values at each hour. The PWP values of white and black MPBS plants were not significantly different, however, they both were significantly higher than those of values obtained from the CS plants on all sampling dates. These findings suggested that plants in the CS were under severe stress since water stress causes a decrease in PWP (Kirkham, 1990).

The PWP was generally at the highest level early in the morning and decreased during the day, reaching the lowest values around 4 to 5 PM in all treatments, and increasing later in the day as plants recovered from the stress. The PWP values for all treatments were about $13 \%$, $27 \%$, and $32 \%$ lower for plants in the white and black MPBS, and CS, respectively, on 20 Dec. compared to the other sampling dates. The PWP values being significantly lower in the CS plants, especially in the afternoon hours, are most likely due to the changes in water content in the containers during the day. Although the plants in the CS were irrigated daily, because of the very low water holding capacity of the substrate the water content in the container decreased rapidly due to drainage, evaporation losses, and plant uptake. Thus, late in the afternoon, there was not enough moisture remained in the substrate resulting in lower PWP. However, this may not be the only reason for low PWP because other environmental factors such as high substrate and root-zone temperatures can influence the root water uptake even if water is not a limiting factor for plant growth. The PWP results support our previous findings in terms of diurnal patterns of the $r_{s}$ and CWSI that plants grown in the white MPBS experienced less stress compared to the plants grown in other treatments.

Substrate temperatures. The hourly STs measured at $0.09-\mathrm{m}$ depth in the containers for each treatment (W2, B2, and CS) for each plant stress sampling date are presented in Figs. 12A and $\mathrm{B}$ and $13 \mathrm{~A}$ and $\mathrm{B}$. Air temperatures were also included in the figures for comparison. Because the ST patterns were similar for all measurement dates, only one day of hourly patterns of the STs will be discussed in detail.

Figures showed that the ST of the white MPBS plants had lower values throughout the day compared to the plants in the black MPBS and CS. On 21 July (Fig. 12A), the maximum ST was about $42.8^{\circ} \mathrm{C}$ in the control treatment at 6 PM whereas the maximum STs of the white and black MPBSs, respectively, were 32.5 and $34.9^{\circ} \mathrm{C}$. The maximum air temperature on that day was $36.8^{\circ} \mathrm{C}$ at 4 PM. Thus, the ST in the white MPBS was $10.3,2.4$, and $4.3^{\circ} \mathrm{C}$ lower than the STs of CS, black MPBS, and air temperatures, respectively. Note that the maximum ST of CS was $6^{\circ} \mathrm{C}$ higher than the air temperature. All temperatures started rising around noon and the rate of temperature rising in the white MPBS was the slowest. The white and black MPBSs and the CS responded similarly to maximum ambient temperature with 4- (white and black MPBSs) and 3-h (CS) phase delays. The ambient temperature started decreasing rapidly at 5 PM. The STs in the white and black MPBSs started to decrease slowly after 8 PM and the ST in the CS started decreasing after $7 \mathrm{PM}$ with the ST in the MPBSs cooling down at a slower rate than the CS. This is an important buffering response of the MPBS since the sudden temperature fluctuations can cause significant stress on plant roots and can negatively influence the plant growth.

Similar results were observed on 25 July (Fig. 12B) and 20 Sept. (Fig. 13A). On these days, the STs of the white MPBS were 3.4 and $2.7^{\circ} \mathrm{C}$ lower than the STs in the black MPBS in the afternoon hours, and they were 13.6 and $9.9{ }^{\circ} \mathrm{C}$ lower than the STs in the CS. On 20 Dec. (Fig. 13B), the STs and air temperature were much lower compared to those obtained in the other sampling dates and the STs in the white and black MPBS were closer and the differences between the two STs were lower. The data analyses of the seasonal pattern of the STs (results are not shown) indicated similar patterns of STs throughout the two seasons that were obtained on four sampling dates. Thus, results indicated that the white color MPBS provided more optimum environment for root development and plant growth when the effectiveness of the system for buffering against the extreme ambient temperature is considered.
Levitt (1980) and Nielsen (1974) stated that the optimum root temperature is lower than the optimum leaf and stem temperatures for optimum plant growth. However, roots are less adaptive to temperature extremes (low and high), and are more sensitive to sudden temperature fluctuations. The roots of most plants would be injured or the level of plant stress would increase if the root-zone is exposed to the same variations and durations of temperature to which the stems are subjected. Kramer (1983) reported that at extremely hot temperatures, the surface soil becomes hot enough to affect or even stop root growth, affect $\mathrm{CO}_{2}$ assimilation, and reduce root water absorption, thus causing severe stresses on the plants. This is evident in our results. As stated earlier in the paper, the root dry weights of the plants in the white MPBS, which always had lower substrate temperatures, were significantly higher compared to the black MPBS and CS that had greater substrate temperatures.

As reported earlier in the CWSI section, plants grown in the white and black MPBSs were under some stress even though they were not under water limiting conditions. Thus, the ST results lead us to conclude that a part of the CWSI values of the plants in the white and black MPBSs as well as the plants in the $\mathrm{CS}$, was attributed to the heat-induced stresses caused by high STs.

\section{CONCLUSIONS}

The black and white color MPBS were investigated during the two growing seasons (summer and fall) in 2001 in north-central Florida climatic conditions to quantify and analyze plant growth and stress parameters for container-grown Viburnum odoratissimum (Ker-gawl). In both seasons, plants in the white MPBS had significantly higher GI and growth rates compared to plants grown in the black MPBS and CS. In the summer season, plants in the white MPBS reached marketable size about 17 and $86 \mathrm{~d}$ earlier than those in the black MPBS and CS, respectively, and in the fall, they reached marketable size about 25 and $115 \mathrm{~d}$ earlier than those plants in the black MPBS and CS, respectively. In both seasons, plants in the white MPBS had lower $r_{s}$ values to vapor transport, lower CWSI, and higher (wetter) PWP values compared to the plants in the black MPBS and CS. Thus, plants in the white MPBS were exposed to the lower levels of plant stresses enhancing plant growth. The high CWSI values of the plants grown in the black MPBSs as well as for the plants grown in the CS was partially attributed to the heat-induced stress caused by high substrate temperatures.

Overall, the white MPBS provided a better environment for root development and plant growth. These findings suggest that in practice, producing nursery plants in a shorter period of time by using white MPBS will result in significant savings of energy, water, chemicals, and other inputs and reduce the cost of production. Based on the experimental results of the two growing seasons, it is concluded that the use of a white color MPBS may be economically 
more viable than the black MPBS and CS for growing Viburnum odoratissimum under these and similar climatic conditions. Currently, further evaluations of using the white MPBS for container-grown plants are being conducted in pilot nurseries. Further research is needed to confirm and/or analyze the superiority of the white MPBS for growing other nursery plants in similar or different climates.

\section{Literature Cited}

Allen, R.G., M. Smith, A. Perrier, and L.S. Pereira 1994a. An update for the definition of reference evapotranspiration. ICID Bul. 43(2):1-34.

Allen, R.G., M. Smith, L.S. Pereira, and A. Perrier. 1994b. An update for the calculation of reference evapotranspiration. ICID Bul. 43(2):35-92.

Allen, R.G., L.S. Pereira, D. Raes, and M. Smith. 1998. Crop evapotranspiration. Guidelines for computing crop water requirements, p. 300 . FAO Irr. and Drain. Paper 56. FAO, Rome, Italy.

Anonymous, 1997. Grades and standards for nursery plants. Fla. Dept. Agr. Consumer Serv., Gainesville.

Caldwell, M.M. 1970. Plant gas exchange at high wind speeds. Plant Physiol. 46:535-537.

Davies, W.J., T.T. Kozlowski, and J. Pereira. 1974. Effect of wind on transpiration and stomatal aperture of woody plants. Bul. R. Soc. N.Z. 12:433-438.

Gardner, B.R., D.C. Nielsen, and C.C. Shock. 1992. Infrared thermometry and the crop water stress index. II. Sampling procedures and interpretation. J. Prod. Agr. 5(4):466-475.

Haman, D.Z., T.H. Yeager, R.C. Beeson, Jr., and G.W. Knox. 1998. Multiple pot box for container plant production. J. Environ. Hort. 16(1):60-63.

Howell, T.A., J.L. Hatfield., H. Yamada, and K.R. Davis. 1984. Evaluation of cotton canopy temperature to detect crop water stress. Trans. Amer. Soc. Agr. Eng. 27:84-88.
Idso, S.B., R.D. Jackson, P.J. Pinter, Jr., R.J. Reginato, and J.L. Hatfield. 1981. Normalizing the stress degree day for environmental variability. Agr. Meteorol. 24:45-55.

Idso, S.B. 1982. Non-water-stressed baselines: A key to measuring and interpreting plant water stress. Agr. Meteorol., 27:59-70.

Irmak, S., D.Z. Haman, and R. Bastug. 2000. Determination of crop water stress index for irrigation timing and yield estimation of corn. Agron. J. 92:1221-1227.

Irmak, S., D.Z. Haman, T.H. Yeager, and C. Larsen. 2001. Seasonal irrigation water use efficiency of multi-pot box system. J. Environ. Hort. 19(1):4-10.

Irmak, S. 2002. A new irrigation-plant production system for water conservation in ornamental nurseries. PhD diss. Univ. Fla., Gainesville.

Irmak, S., D.Z. Haman, A. Irmak, J.W. Jones, K.L. Campbell, and T.H. Yeager. 2003. New irrigation-plant production system for water conservation in ornamental nurseries: Quantification and evaluation of irrigation, runoff, plant biomass, and irrigation efficiencies. Appl. Eng. Agr. ASAE 19(6):651-665.

Jackson, R.D., S.B. Idso. R.J. Reginato, and P.J. Pinter, Jr. 1981. Canopy temperature as a crop water stress indicator. Water Resour. Res. 17:1133-1138.

Jackson, R.D. 1982. Canopy temperature and crop water stress, p. 43-85. 1982. In: D. Hillel (ed.). Advances in irrigation. vol. I. Academic Press, New York.

Kabashima, J.N. 1993. Innovative irrigation techniques in nursery production to reduce water usage. HortScience 28(4):291-292.

Karam, N.K. and A.X. Niemiera. 1994. Cyclic sprinkler irrigation and pre-irrigation substrate water content affect water and $\mathrm{N}$ leaching from containers. J. Environ. Hort. 12:198-202.

Kirkham, M.B. 1990. Plant responses to water deficits, p. 324-338. In: S.H. Mickelson (ed.). Irrigation of agricultural crops. ASA-CSSA-SSSA Agron. Monogr. Ser. 30.
Knoerr, K.R. 1967. Contrasts in energy balances between individual leaves and vegetated surfaces, p. 391-401. In: W.E. Sopper and H.W. Lull (eds.). Intl. Symp. forest hydrology. Pergamon, Oxford.

Kramer, P.J. 1983. Water relations of plants, p. 489. Academic Press, New York.

Levitt, J. 1980. Responses of plant to environmental stresses. vol. 1. Chilling, freezing, and high temperatures stresses. Academic Press, New York.

Nielsen, D.C. and B.R. Gardner. 1987. Scheduling irrigations for corn with the crop water stress index (CWSI). Appl. Agr. Res. 2(5):295-300.

Nielsen, K.F. 1974. Roots and root temperature, p. 691. In: E.W. Carson (ed.). The plant root and its environment. Univ. Press, Charlottesville, Va.

O'Toole, J.C., N.C. Turner, O.P. Namuco, M. Dingkukn, and K.A. Gomez. 1984. Comparison of some crop water stress measurement methods. Crop Sci. 24:1121-1128.

Pinter, Jr., P.J. and R.J. Reginato. 1982. A thermal infrared technique for monitoring cotton water stress and scheduling irrigation. Trans. Amer. Soc. Agr. Eng. 25:1651-1655.

Reginato, R.J. 1983. Field quantification of crop water stress. Trans. Amer. Soc. Agr. Eng. 26(3):772-775

Reginato, R.J. and J. Howe. 1985. Irrigation scheduling using crop indicators. J. Irr. Drain. Eng. $3: 125-133$.

Reginato, R.J., and D.J. Garrett, Jr. 1987. Irrigation scheduling with the crop water stress index, $\mathrm{p}$. 7-10. Western Cotton Production Conf. Summary Proc.

Wanjura, D.F., J.L. Hatfield, and D.R. Upchurch. 1990. Crop water stress index relationship with crop productivity. Irr. Sci. 11:93-99.

Weatherspoon, D.M., and C.C. Harrel. 1980. Evaluation of drip irrigation for container production of woody landscape plants. HortScience 15:488-489. 